\title{
The Digital Divide in Online Education: A Study of Underserved College Students
}

\author{
Xuefei (Nancy) Deng \\ California State University Dominguez Hills \\ ndeng@,csudh.edu
}

\author{
Sheng Yi \\ California State University Dominguez Hills \\ syi@csudh.edu
}

\begin{abstract}
Access to technology is essential to educational success in today's digitized society, but disparities in access to technology can handicap students. This study examines to what extent this digital divide exists among underserved students in online instruction during COVID-19 and in their adoption of free Technology Loaner programs. Focusing on underserved students that are characterized by their generational status, minority background or low income, we predict that underserved college students will show lower levels of technology access and higher levels of free technology adoption than their counterparts. However, the quantitative analysis of survey data $(n=258)$ collected from a U.S. minority-serving university provides mixed, surprising results. Follow-up analysis of qualitative data from 10 interviews offers us further insights and partial explanations for these unexpected results. Our study suggests that individual background should be considered in designing a policy to mitigate digital divide and enhance student learning in online education.
\end{abstract}

\section{Introduction}

In today's digitized society, access to information and communication technology (ICT) is essential to educational success. Such access is especially important for underserved students, who do not receive equitable educational and career planning opportunities and resources compared to other students in the academic pipeline. In the U.S., underserved students have at least one of the following characteristics: (1) belong to a minority group (i.e. race/ethnicity is African American, American Indian/Alaska Native, Hispanic/Latino, or Native Hawaiian/other Pacific Islander), (2) have a low income (i.e. combined annual parent income is less than or equal to $\$ 36,000$ ), or (3) are the first generation to attend college (i.e. highest parental education level is high school diploma or less) [1]. It is critical for institutions of higher education to provide equitable resources to underserved students to help them succeed [2]. During the ongoing coronavirus
(COVID-19) pandemic, the gap in student access to computing resources has widened and its negative impact on online educational continuity has profoundly affected underserved student populations. For example, a recent study of minority students in a four-year public university in the U.S. suggests that the pandemic in the U.S. that started in the spring of 2020 and disrupted face-to-face classes gave rise to five types of digital barriers - slow Internet speed, technical problems, lack of computer resources, lack of Internet access, and skill deficiencies - in the sudden transition of in-person classes to online instruction [3].

However, disparities in technology access persist among students from different geographical locations, income and ethnic backgrounds. According to a comprehensive report based on several national surveys in the spring or summer of 2020, and a large-scale survey conducted at Indiana University and the Ohio State University in the U.S. during the same time period, $16 \%$ - 19\% of college students reported technology barriers (i.e., inadequate computer hardware or Internet connection) during the COVID-19 emergency shift to online instruction [4]. Among all the college students in those national surveys, students who were from lowerincome families, from minority backgrounds (i.e., Black, Hispanic) or lived in a rural areas experienced higher rates of technology inadequacy.

The gap between people who have sufficient access to and knowledge of technology and those who do not is commonly referred to as the digital divide $[5,6]$. Such technology barriers inhibited college students' participation in online learning during the COVID-19 pandemic. For policy makers and education leaders, it is important to understand the current status of the digital divide in online education, especially during the pandemic [4]. Thus, this study examines if substantial differences exist between underserved students and their peers with regard to their access to ICT at home for online instruction. In particular, our first research question is: To what extent have underserved college students and their peers differed in their access to information and communication technology at home for online instruction? 
Both government and educational institutions have increased funds to tackle the problem of the digital divide during the pandemic. For example, in March 2020, the U.S. congress passed the Coronavirus Aid, Relief, and Economic Security (CARES) Act, providing educational institutions in the U.S. with CARES funds for upgrading their educational technology infrastructure and resources. During the 2020-2021 academic year, U.S. educational institutions increased their investment in computer devices and Internet services, offering a variety of loaner programs to enable eligible students to check out laptops and mobile Wi-Fi devices at no charge to support their online classes at home. For policy makers and education leaders, it is important to understand the effect of those technology initiatives (such as the Technology Loaner programs) in closing the digital gap among college students. Therefore, this study addresses the second question: To what extent have underserved college students and their peers differed in adopting the free computing resources provided by universities during the pandemic?

This study focuses on underserved college students who are characterized by their low socioeconomic status, minority background, or first-generation student status. In particular, first-generation college students (FGCS) are underserved students who enroll in postsecondary education with neither of their parents having a four-year college (i.e., Bachelor's) degree. In the United States, as of academic year 2015-16, this group represented $56 \%$ of all undergraduate students, according to data from the U.S. Department of Education [7]. A deeper analysis of the digital divide experienced by FGCS is important for two major reasons. First, higher education institutions continue to face challenges in increasing the college retention and graduation rate of FGCS [8, 9]. For example, the dropout rate for FGCS is much higher than that of their counterparts, continuing-generation college students (CGCS) [10]. Understanding the technology access by FGCS is critical for higher education institutions to identify and implement strategies for improving their college success. Second, there have been many calls over recent decades for information systems (IS) researchers to focus more attention on studies that have a real impact on societal issues [11]. As IS academics who care not only about the rigor and relevance but also the social ramifications of our research, we have a moral responsibility to address important societal problems to develop knowledge that benefits business and the society [12].

Informed by digital divide research, we predict that underserved college students (i.e., FGCS, minority, and low income) will show a lower level of technology access than their peers. Similarly, we predict that underserved students are more likely to adopt the free laptop loaner program than their peers. To test our hypotheses, we collected survey data in March 2021 from 259 underserved students in a minority-serving university in the United States. The quantitative data analysis provided surprising, mixed results. To explain the surprising result, we conducted follow-up interviews and analyzed qualitative data for insights.

The findings of this study have important practical implications for the success of underserved students in higher education, conducive to enhancing their career success and socioeconomic status. By investigating the digital divide problem among underserved student groups during the COVID-19 pandemic, we respond to the IS research call to study the role of technology in addressing societal issues [11, 12]. Moreover, the findings of this study provide insights into the social equity issues emphasized by this conference minitrack on "Addressing Diversity in Digitalization."

\section{Theoretical background}

Two streams of research broadly inform our study: underserved students in higher education and the digital divide. The literature on underserved students informs our understanding about the characteristics of this student population, as well as their college persistence and challenges. We then draw upon the literature on the digital divide to predict differences in the access to technology resources between underserved students and their counterparts, through which to build our hypotheses in the context of online education during the COVID-19 pandemic.

\subsection{Underserved students in higher education}

Previous research indicates that underserved students (i.e., FGCS, low-income students, or minorities) have more negative college outcomes, such as low retention and completion rates. According to Schudde and Clayton's research [13] on Pell Grant recipients (need-based financial aid), $45 \%$ of Pell Grant recipients entering postsecondary institutions do not enroll for a second year of college. Redford and Hoyer's report published in 2017 [9] analyzed a nationally representative sample of high school sophomores who were followed from 2002 through 2012. They found FGCS who had obtained a bachelor's degree were much lower than that of CGCS, at $20 \%$ and $42 \%$ respectively. Cahlan and Perna [14] showed that individuals from the highest-income families were eight times more likely than individuals from low-income families to obtain a bachelor's degree by age 24 in 2013 and this gap is increasing over time. Survey data from the 2015-16 National Postsecondary Student Aid Study (NPSAS:16) in the U.S. indicated that $43 \%$ of whites between the 
ages of 25-29 had attained a postsecondary degree in 2015, versus $21 \%$ of Black students and $16 \%$ of Hispanic students [15].

Those three factors (i.e., FGCS, low-income and minority) that identify underserved students are highly correlated. For example, compared to CGCS, FGCS are more likely to come from ethnic and racial minority backgrounds and thus are less likely to be well prepared academically. They are more likely to be older and less likely to receive financial support from parents, and more likely to have multiple obligations outside college [16]. Using survey data from the 2015-16 National Postsecondary Student Aid Study (NPSAS:16), analysis from RTI International [7] shows that among FGCS (CGCS), 46\% (61\%) are White, 18\% (12\%) are Black/African American, 25\% (14\%) are Hispanic/Latino, and $6 \%(8 \%)$ are Asian. Median parental income among dependent students is $\$ 41,000$ $(\$ 90,000)$ for FGCS (CGCS), respectively.

To help underserved students overcome challenges, achieve academic success, and graduate from college, many universities provide social- and academic-support programs, such as peer groups, residential colleges, academic departments, ethnic student organizations, sports teams, off-campus volunteer groups, and student government, which have proven to be effective [8]. These programs give minority students a sense of belonging, which is positively correlated with college persistence [17]. In addition, through such programs, students develop a higher sense of their academic selfefficacy. Using an academic self-efficacy scale, Azmitia et al. [18] found that the self-efficacy of FGCS contributes to their college persistence. In addition, Schwartz et al. [19] studied the effects of a skill development and attitude invention program on FGCS in an ethnically diverse, urban public university in northeastern US. Their data analysis provided evidence of the positive effect of students' help-seeking behaviors from peers and relationship-building with instructors on their successful transition from high school to college life during the first year, including higher GPAs at the end of the year. These studies have shown that underserved students could benefit from interactions with teachers, advisors, and classmates with whom they are able to forge relationships and obtain valuable information resources that help them persist through their college years.

Although insightful, the literature outlined above underscores how technology has penetrated higher education institutions and increasingly affected the academic study and success of college students. Information and communication technology has been used to support core teaching and learning activities in online education [20]. In addition, online resources such as massive open online courses have been used by underserved students to broaden access to higher education. Those resources have removed many of the institutional barriers standing before low-income and minority students [15]. Yet, the effectiveness of online learning and collaborative activities depends on technological affordances. According to Kirschner et al. [21], technological affordances refer to the presence of specific tools and artifacts such as videoconferencing or workgroup support system that supports collaborative tasks. In particular, technological affordances help accomplish learning goals by facilitating and maintaining member participation, information exchanges, and interactions to the team learning process. As more classroom instruction is delivered on digital platforms, student access to technology resources is critical to their college learning and experience. Below we review the literature on the digital divide for further insights.

\subsection{Digital divide}

The U.S. Department of Commerce's National Telecommunications and Information Administration (NTIA) officially used the term for the first time in its third "Falling through the Net" publication [5]. "Digital divide" refers to "the divide between those with access to new technologies and those without" [6]. The initial conceptualization of the digital divide is based on a binary classification of physical access to computers and the Internet, i.e., the gap between those who have access and those who have not. Within this context, the digital divide reflects the socioeconomic inequality in having access to computers and the Internet [5]. In the decade after the NTIA report, researchers further developed the concept of the digital divide by distinguishing four areas of importance: attitudes, access, skills, and types of usage [22, 23, 24].

During the past two decades, the gap between the Haves and the Have Nots may have become smaller, yet the gap persists. According to a recent study by Van Deursen and Van Dijk [25], the access to digital technology remains a problem in the Netherlands, one of the most affluent and technologically developed countries in the world. Their study concludes that "a diversity in access to devices and peripherals, devicerelated opportunities, and the ongoing expenses required to maintain the hardware, software, and subscriptions affect existing inequalities related to Internet skills, uses, and outcomes" [25, p.354].

To understand and close the digital divide, scholars have paid attention to the factors contributing to it. For example, physical access to computers, the Internet, and other technologies have been viewed as technological opportunities that correlated with income, education, age, gender, and ethnicity [26]. Consistently, digital 
divide research has shown that lower income and other socioeconomic factors (such as education and ethnicity) are correlated with the digital divide [27]. As underserved students are associated with low socioeconomic status, minority background, or coming from families where parents do not have more than a secondary education, underserved students are likely to differ from their peers in access to technology resources for online instruction. Therefore, we predict:

Hypothesis 1: Underserved college students are more likely to show lower levels of access to information and communication technology at home than their counterparts.

Inequalities in both the access to and use of ICT will negatively impact our communities and society at large. As Notley [28] suggests, access to and proficiency in ICT are critical for high risk and underserved populations to improve their lives and socioeconomic opportunities. There is little research directly examining the impact of the digital divide for FGCS. Recent research from Deng and Yang analyzed a data sample ( $\mathrm{n}$ = 309) collected from a minority-serving university in the U.S. and found that FGCS underperformed in digital proficiency, compared to their peers [29]. Therefore, we predict:

Hypothesis 2: Underserved college students are more likely to show higher levels of adoption of university's Technology Loaner programs than their counterparts.

\section{Method}

We adopt mixed methods (quantitative and qualitative) to achieve our research objectives, i.e., to what extent the digital divide exists between underserved students and their peers and to investigate the underlying reasons. ANOVA was used for the quantitative data analysis to test the hypotheses, and qualitative data analysis was used to find explanations for the unsupported and surprising quantitative results. The mixed methods of qualitative and quantitative analysis complement each other and potentially provide a richer exploration of the linkages across variables [30].

\subsection{Research site}

The research site is a four-year U.S. public university that is designated as a minority-serving institution. Consistent with the definition by the U.S. Department of Education [31], we consider minorityserving institutions as institutions of higher education that enroll a high percentage of minority students such as African American, American Indian, Hispanic/Latino, and Pacific Islander. At the research site, the economically and ethnically diverse student population includes $60 \%$ Hispanic or Latino, $15 \%$ Black or African American, 11\% White, 11\% Asian, and 3\% others. More than half of the enrolling students (54\%) are first generation and $64 \%$ are eligible for a Pell grant, the U.S. federal grant usually awarded to undergraduate students who display exceptional financial needs. Given the socioeconomic backgrounds of the student population, this university is an ideal research site for us to study underserved college students and the digital divide in online education.

The data reported in this paper are part of a larger project that was funded by the University President's Challenge to enhance digital skills and competence of underserved students at the University. That large project examined college students' educational resources, technology barriers, motivation to improve their digital skills (such as using Microsoft Excel), and their overall learning challenges.

\subsection{Data collection}

Data were collected during a two-week period in early March of 2021 through an online questionnaire distributed to 360 undergraduate students. This data was gathered through a convenience sampling. In the online survey, students were invited to share their experience of taking all classes online, including their Internet access and computer resources and their use of the Technology Loaner program offered by the university. The survey included questions on students' demographic background information, such as age, gender, ethnicity, employment status, and household income.

To measure the digital divide, we asked the participants to indicate their level of agreement with two statements (1) I have adequate computing resources (e.g., computer, webcam, headset) at home and (2) My Internet connection at home is adequate on a 5-point Likert scale. The two survey items were adopted in recent national surveys and study on technological barriers in online education during the COVID-19 pandemic ([3], [4], [32]).

To measure their adoption of the university's Technology Loaner Program, we asked the participants to indicate their level of agreement with three statements (1) I have used the Technology Loaner Program to check out a laptop from the university, (2) I have used the Technology Loaner Program to check the $\mathrm{MiFi}$ (a wireless router that acts as a mobile Wi-Fi hotspot) devices from the university, and (3) I have used the Technology Loaner Program to check out other devices (e.g., headsets with microphones, webcams) from the university. The three survey items matched the three types of Technology Loaner programs supported 
by the CARES fund at the University. For both measures, we used the 5-point Likert scale, with 1 meaning "Disagree Strongly", 2 meaning "Disagree", 3 meaning "Neutral", 4 meaning "Agree" and 5 meaning "Agree Strongly."

On average, each survey took the participants 11 minutes to complete. We collected a total of 259 completed surveys, resulting in a $72 \%$ response rate (259 of 360 students). Among the 259 responses, one student did not answer the FGCS status question. Removing that data record, we used the data sample 258 for our final data analysis. Table 1 summarizes the demographic characteristics of the 258 participants in the study.

\begin{tabular}{|c|c|c|c|c|c|}
\hline \multicolumn{6}{|c|}{ Table 1. Sample characteristics $(n=258)$} \\
\hline & FGCS & $\%$ & CGCS & $\%$ & Total \\
\hline \multicolumn{6}{|l|}{ By Gender } \\
\hline Female & 136 & $84.0 \%$ & 26 & $16.0 \%$ & 162 \\
\hline Male & 76 & $80.0 \%$ & 19 & $20.0 \%$ & 95 \\
\hline $\begin{array}{l}\text { Gender Non- } \\
\text { Conforming } \\
\end{array}$ & 1 & $100.0 \%$ & 0 & $0.0 \%$ & 1 \\
\hline \multicolumn{6}{|l|}{ By Ethnicity } \\
\hline Asian American & 6 & $37.5 \%$ & 10 & $62.5 \%$ & 16 \\
\hline $\begin{array}{l}\text { Black/African } \\
\text { American }\end{array}$ & 24 & $80.0 \%$ & 6 & $20.0 \%$ & 30 \\
\hline Caucasian/White & 10 & $58.8 \%$ & 7 & $41.2 \%$ & 17 \\
\hline Latino/Chicano & 159 & $89.8 \%$ & 18 & $10.2 \%$ & 177 \\
\hline $\begin{array}{l}\text { Other (please } \\
\text { specify) }\end{array}$ & 11 & $73.3 \%$ & 4 & $26.7 \%$ & 15 \\
\hline (blank) & 3 & $100.0 \%$ & 0 & $0.0 \%$ & 3 \\
\hline \multicolumn{6}{|l|}{$\begin{array}{l}\text { By Household } \\
\text { income }\end{array}$} \\
\hline $\begin{array}{l}\text { Less than } \\
\$ 20,000\end{array}$ & 44 & $91.7 \%$ & 4 & $8.3 \%$ & 48 \\
\hline$\$ 20,000-\$ 39,999$ & 70 & $84.3 \%$ & 13 & $15.7 \%$ & 83 \\
\hline$\$ 40,000-\$ 59,999$ & 43 & $89.6 \%$ & 5 & $10.4 \%$ & 48 \\
\hline$\$ 60,000-\$ 74,999$ & 26 & $76.5 \%$ & 8 & $23.5 \%$ & 34 \\
\hline$\$ 75,000-\$ 99,999$ & 14 & $77.8 \%$ & 4 & $22.2 \%$ & 18 \\
\hline $\begin{array}{l}\$ 100,000 \text { or } \\
\text { more }\end{array}$ & 12 & $57.1 \%$ & 9 & $42.9 \%$ & 21 \\
\hline (blank) & 4 & $66.7 \%$ & 2 & $33.3 \%$ & 6 \\
\hline \multicolumn{6}{|l|}{$\begin{array}{l}\text { By Employment } \\
\text { Status }\end{array}$} \\
\hline $\begin{array}{l}\text { Employed full- } \\
\text { time }\end{array}$ & 69 & $84.1 \%$ & 13 & $15.9 \%$ & 82 \\
\hline $\begin{array}{l}\text { Employed part- } \\
\text { time }\end{array}$ & 67 & $84.8 \%$ & 12 & $15.2 \%$ & 79 \\
\hline $\begin{array}{l}\text { Not employed } \\
\text { (Student Only) }\end{array}$ & 64 & $77.1 \%$ & 19 & $22.9 \%$ & 83 \\
\hline $\begin{array}{l}\text { Other (please } \\
\text { specify) }\end{array}$ & 13 & $92.9 \%$ & 1 & $7.1 \%$ & 14 \\
\hline Grand Total & 213 & $82.6 \%$ & 45 & $17.4 \%$ & 258 \\
\hline
\end{tabular}

Among the 258 participants, 213 (82.6\%) were FGCS and 45 (17.4\%) were CGCS. The respondents were mostly female (62.8\%), Latino/Chicano (68.6\%), and full-time or part-time employed (62.4\%). Half of the participants $(50.8 \%)$ came from families with a total household income less than $\$ 40,000$.

We also conducted follow-up interviews in May 2021 with 10 students recruited from the participants of Excel Skills Workshops at the University. Each interview lasted 30 minutes, and each participant received a \$20 Amazon gift card to compensate them for their interview time. We did not conduct more than 10 interviews because no more new themes emerged from students' narratives. During those interviews, we asked respondents open-ended questions such as "During the transition to online learning during the COVID-19, have you ever experienced digital barriers such as lack of computer and fast Internet connections?" "What kinds of computer resources do you have at home to support you to take online classes during the past year?"

Our interview protocol also included open-ended questions about students' experiences with access to free computer resources at university, such as "The university offered students the Technology Loaner Program to allow students to check out a laptop the MiFi internet devices for free use. Have you used the Technology Loaner Program?" "Do you think the Technology Loaner Program is helpful to students? Why or why not? Please use an example to illustrate your points, based on your experience or experiences of other students." The interviews were conducted via Zoom and were recorded and transcribed for data analysis.

\section{Quantitative data analysis and results}

We first performed the descriptive analysis of the two key variables - digital divide and technology loaner adoption - through the lens of three characteristics (generational status, minority background, and low income) of underserved students. First generation college student (FGCS) is defined as students who answered "Yes" in the survey question, "Are you a firstgeneration student (e.g., neither one of your parents has a four-year degree, i.e. B.A., B.S.)?" Continuinggeneration college students (CGCS) is defined as students who answered "No" to this survey question. Minority is defined as students who self-reported as "Black/African American", "Latino/Chicano" or "Native American" in the survey question, "What is your ethnic background?" Non-minority is defined as students who identified themselves as "Asian American", "Caucasian/White" and "Other" in this survey question. Household Income Less than $\$ 40,000$ is defined as students who chose the categories of "Less 
than $\$ 20,000 "$ and " $\$ 20,000-\$ 39,999 "$ to the survey question, "What is the total annual income of your household?" Household Income $\$ 40,000+$ is defined as students who indicated household income at $\$ 40,000$ or more in the survey.

Table 2 presents the descriptive statistics of the two digital divide measures: Digital Divide 1 (on computing resources) and Digital Divide 2 (on home Internet connection).

\begin{tabular}{|c|c|c|c|}
\hline & Mean & Std & Count \\
\hline \multicolumn{4}{|c|}{ Digital Divide 1} \\
\hline \multicolumn{4}{|l|}{ Generation Status } \\
\hline FGCS & 4.39 & 0.77 & 212 \\
\hline CGCS & 4.31 & 1.00 & 45 \\
\hline \multicolumn{4}{|l|}{ Ethnicity } \\
\hline Minority & 4.44 & 0.77 & 208 \\
\hline Non-Minority & 4.15 & 0.98 & 47 \\
\hline \multicolumn{4}{|l|}{ Household Income } \\
\hline Less than $\$ 40,000$ & 4.28 & 0.87 & 130 \\
\hline$\$ 40,000+$ & 4.49 & 0.74 & 122 \\
\hline Whole Sample & 4.38 & 0.82 & 258 \\
\hline \multicolumn{4}{|c|}{ Digital Divide 2} \\
\hline \multicolumn{4}{|l|}{ Generation Status } \\
\hline FGCS & 4.30 & 0.77 & 212 \\
\hline CGCS & 4.33 & 0.77 & 45 \\
\hline \multicolumn{4}{|l|}{ Ethnicity } \\
\hline Minority & 4.32 & 0.77 & 207 \\
\hline Non-Minority & 4.23 & 0.81 & 48 \\
\hline \multicolumn{4}{|l|}{ Household Income } \\
\hline Less than $\$ 40,000$ & 4.18 & 0.84 & 131 \\
\hline$\$ 40,000+$ & 4.44 & 0.67 & 121 \\
\hline Whole Sample & 4.30 & 0.77 & 258 \\
\hline
\end{tabular}

Table 3 presents the descriptive statistics for the three measures of technology loaner adoption (TLA), including checking out for free from the university a laptop (TLA1), the MiFi (TLA2), and other devices (e.g., headsets with microphones, webcams) (TLA3).

We performed one-way analysis of variance (ANOVA) to test the effect of underserved students' generational status, minority background, and household income on the digital divide (Hypothesis 1) and on technology loaner adoption (Hypothesis 2). For Hypothesis 1, the one-way ANOVA did not show a significant effect of generational status on the two digital divide measures: $F(1,255)=0.36$ and $\mathrm{p}=0.55$ for digital divide measure 1 and $F(1,255)=0.08$ and $p=0.78$ for digital divide measure 2. However, the effect of minority background on one measure (digital divide 1) is significant, $F(1,255)=4.89, p=0.03$. Moreover, the effect of income level is significant on both measures of the digital divide: $F(1,250)=4.42$ and $p=0.04$ for digital divide measure 1 and $F(1,250)=7.48$ and $p=0.01$ for digital divide measure 2 .

\begin{tabular}{|c|c|c|c|}
\hline \multicolumn{4}{|c|}{$\begin{array}{l}\text { Table 3. Descriptive analysis: technology } \\
\text { loaner adoption }\end{array}$} \\
\hline & Mean & Std & Count \\
\hline \multicolumn{4}{|c|}{ Technology Loaner Adoption 1} \\
\hline \multicolumn{4}{|l|}{ Generation Status } \\
\hline FGCS & 1.92 & 1.39 & 207 \\
\hline CGCS & 2.39 & 1.56 & 44 \\
\hline \multicolumn{4}{|l|}{ Ethnicity } \\
\hline Minority & 1.93 & 1.41 & 203 \\
\hline Non-Minority & 2.26 & 1.47 & 47 \\
\hline \multicolumn{4}{|l|}{ Household Income } \\
\hline Less than $\$ 40,000$ & 2.04 & 1.42 & 126 \\
\hline$\$ 40,000+$ & 1.95 & 1.43 & 121 \\
\hline Whole Sample & 2.00 & 1.43 & 252 \\
\hline \multicolumn{4}{|c|}{ Technology Loaner Adoption 2} \\
\hline \multicolumn{4}{|l|}{ Generation Status } \\
\hline FGCS & 1.78 & 1.27 & 212 \\
\hline CGCS & 1.98 & 1.31 & 45 \\
\hline \multicolumn{4}{|l|}{ Ethnicity } \\
\hline Minority & 1.68 & 1.18 & 207 \\
\hline Non-Minority & 2.31 & 1.49 & 48 \\
\hline \multicolumn{4}{|l|}{ Household Income } \\
\hline Less than $\$ 40,000$ & 1.90 & 1.32 & 130 \\
\hline$\$ 40,000+$ & 1.70 & 1.22 & 122 \\
\hline Whole Sample & 1.81 & 1.28 & 258 \\
\hline \multicolumn{4}{|c|}{ Technology Loaner Adoption 3} \\
\hline \multicolumn{4}{|l|}{ Generation Status } \\
\hline FGCS & 1.69 & 1.18 & 212 \\
\hline CGCS & 1.93 & 1.21 & 45 \\
\hline \multicolumn{4}{|l|}{ Ethnicity } \\
\hline Minority & 1.60 & 1.08 & 207 \\
\hline Non-Minority & 2.27 & 1.45 & 48 \\
\hline \multicolumn{4}{|l|}{ Household Income } \\
\hline Less than $\$ 40,000$ & 1.86 & 1.28 & 130 \\
\hline$\$ 40,000+$ & 1.58 & 1.07 & 122 \\
\hline
\end{tabular}




\section{Whole Sample}

1.73

1.19

258

Table 4 summarizes the one-way ANOVA results for the measures, Digital Divide (DD1-2) and Technology Loaner Adoption (TLA1-3). As shown in Table 4, the one-way ANOVA provided mixed results for Hypothesis 2. Overall, the effect of generational status on technology loaner adoption was not significant (see TLA2 and TLA3), with one exception (TLA1). Opposite to the prediction, the CGCS showed higher adoption of the technology loaner program for checking out laptops, compared to the FGCS.

\begin{tabular}{|c|c|c|}
\hline \multicolumn{3}{|c|}{ Table 4. One-way ANOVA results } \\
\hline Measure & Result & $\begin{array}{l}\text { Hypothesis } \\
\text { Supported? }\end{array}$ \\
\hline \multicolumn{3}{|c|}{ Hypothesis 1: Digital divide } \\
\hline \multicolumn{3}{|c|}{ Panel A: FGCS and CGCS } \\
\hline DD1 & $F(1,255)=0.36, p=.55$ & No \\
\hline DD2 & $F(1,255)=0.08, p=.78$ & No \\
\hline \multicolumn{3}{|c|}{ Panel B: Minority and non-Minority } \\
\hline DD1 & $\mathrm{F}(1,253)=4.89, \mathrm{p}=.03$ & $\mathrm{No}^{*}$ \\
\hline DD2 & $F(1,253)=0.52, p=.47$ & No \\
\hline \multicolumn{3}{|c|}{ Panel C: Income $(<\$ 40 \mathrm{k}$ and $\$ 40 \mathrm{k}+)$} \\
\hline DD1 & $F(1,250)=4.82, p=.04$ & Yes \\
\hline DD2 & $F(1,250)=7.48, p=.01$ & Yes \\
\hline \multicolumn{3}{|c|}{ Hypothesis 2: Technology Loaner adoption } \\
\hline \multicolumn{3}{|c|}{ Panel A: FGCS and CGCS } \\
\hline TLA1 & $F(1,249)=3.86, p=.05$ & No* \\
\hline TLA2 & $F(1,255)=0.90, p=.34$ & No \\
\hline TLA3 & $F(1,255)=1.51, p=.22$ & No \\
\hline \multicolumn{3}{|c|}{ Panel B: Minority and non-Minority } \\
\hline TLA1 & $F(1,248)=2.00, p=.16$ & No \\
\hline TLA2 & $F(1,253)=9.99, p=.00$ & $\mathrm{No}^{*}$ \\
\hline TLA3 & $F(1,253)=13.1, p=.00$ & $\mathrm{No}^{*}$ \\
\hline \multicolumn{3}{|c|}{ Panel C: Income $(<\$ 40 \mathrm{k}$ and $\$ 40 \mathrm{k}+)$} \\
\hline TLA1 & $F(1,245)=0.24, p=.62$ & No \\
\hline TLA2 & $F(1,250)=1.61, p=.21$ & No \\
\hline TLA3 & $F(1,250)=3.52, p=.06$ & Yes \\
\hline
\end{tabular}

(Note: No* means the result is significant but opposite to the predicted direction)

As shown in Table 4, the effect of household income is significant with regard to only one of the three technology adoption measures (TLA3), suggesting that students from low-income families (i.e., < \$40k) are more likely to check out other computer devices such as headsets with microphones and webcams from the university.

For the factor of minority background, the effect on the technology loaner adoption is significant with regard to two measures (TLA2 and TLA3). However, in contrast to the predicted direction, non-minority students were found to be more likely to adopt university loaner programs to check out MiFi and other devices, compared to their minority peers.

\section{Qualitative data analysis and findings}

To understand the surprising, mixed results from the quantitative data analysis, we analyzed the qualitative data from the interviews. For the qualitative data analysis, we followed the research method proposed by Miles and Huberman [33]. We focused on themes in the narratives of 10 interview participants, particularly on their decision rationale for the Technology Loaner Program offered by the university.

Our focus is to understand why some underserved college students (FGCS and minority students) did not show differences from their counterparts in technology access and free resource adoption as predicted. As reported in Tables (2-4), FGCS and minority students have shown more access to computers and Internet resources at home and less adoption of the Technology Loaner Program than CGCS and non-minority as predicted. Three major themes emerged. First, FGCS were mostly minority (Latino/Hispanic) in our study sample. They obtained technology resource access from other channels (such as workplace) rather than from family. Compared to CGCS, FGCS were more likely to be older and employed (full-time or part-time). As a result, they were more likely to obtain computer resources (i.e., laptops, software) from work if they were working in professional workplaces (i.e., in accounting, office administration, and so on). When COVID-19 disrupted work routines and college learning, some FGCS were able to take their computer resources home to continue to work from home while also using those computer resources to access online courses, with the permission of their supervisors. This circumstance is reflected in the following remark:

Last year during the Spring semester around midMarch, all classes were moved from face-to-face interaction to online distance learning. The first barrier that I encountered with this change was not having access to computers and printers. At that time, I did not even have a computer at home. For about a month, I was logging in to my virtual classes from my workplace (with my bosses' permission). The second week of April my employer decided that we all were going to work from home, and I brought into my house the desktop computer from work. (Respondent ID \#1; FGCS; Minority; Junior; major in Accounting)

As indicated above, with the desktop computer moved home from her workplace, the student did not report a lack of computer resources at the time of the data collection in spring 2021 (May 2021), nor did she take advantage of the Technology Loaner Program at university to check out the computer resources for free use. For some other FGCS (with minority background), 
they worked full-time and had secured technology resources for their online classes prior to COVID-19. Their employment had provided them with the financial means to invest in computer resources for online classes even before the pandemic. Two FGCSs explained:

I am currently in my junior year after returning to college about a year ago from military service. I work full time and go to school so COIVD-19 didn't really affect me digitally as I typically take online classes to fit my work schedule. The type of resources I acquired to prepare myself for online class prior to COVID was a laptop and $\mathrm{Mi}-\mathrm{Fi}$ device (Verizon) for great service on the go. (Respondent ID \#5; FGCS; Minority; Junior; major in Information Systems)

I have been very fortunate being a returning older student from a two-income household that I have not had any experience with a digital barrier. Again due to my circumstances, I have access to high speed internet and a working laptop to take online classes [at home]. I also have a tablet that allowed me to attend synchronous classes while at work, as I did not have the opportunity to work from home during much of the pandemic. (Respondent ID \#6; FGCS; Junior; Minority; major in Business Administration/Human Resource Management)

The second theme is that CGCS students from lowincome families reported technology deficiencies at home and used the Technology Loaner Program to resolve their home computing deficiencies for online classes during COVID-19. For example, a CGCS checked out a laptop from the university when his own PC broke during the middle of a semester. He explained: I have used the Technology Loaner Program that [the university] offers during my second semester as my personal computer broke down. Thanks to the program I was able to complete, turn in all assignments, and finish the semester successfully. The program definitely comes in handy for the students who do not have access to technology at home. The best part is that now students are allowed to check out a laptop for a whole year. It is great and has made my college success easier. (Respondent ID \#2; CGCS; Low-income; Junior; major in Business Administration/Human Resource Management)

Finally, whether using the Technology Loaner Program or not, the participants in our study agreed on the importance of having the free computing resources available for college students, especially underserved students, attending the minority-serving institution. The sentiment is reflected in the two remarks below.
I personally worked full time throughout 2020 and have not used the Technology loaner Program. I have heard of other students who have taken advantage of the university's resources and aid. I believe investing in students is truly investing in the future and the first step may be closing the gap of the digital divide. (Respondent ID \#3: FGCS; Minority; Junior: Major in Business Administration)

The Technology Loaner Program I believe is helpful for students because it gives students the opportunity to borrow a laptop and Mi-Fi device to be able to connect online via zoom and get their assignments done. If schools like ours didn't offer this to students, then there would be many people not attending classes or it would make a huge impact on their grades. I have many college friends who don't work or don't have money they can borrow from parents to be able to just buy the devices needed to succeed, so I believe that the loaner program was absolutely necessary. (Respondent ID \#4: CGCS; non-Minority; Junior: Major in Accounting)

\section{Discussions and contribution}

Our objectives were to examine whether a digital divide existed between underserved college students and their counterparts in their online education during the COVID-19 pandemic. Our data shows that underserved students characterized by low-income family background demonstrated the significant needs for technology resources, as we predicted. However, those underserved students measured by their generational status or minority background showed mixed, surprising results. With both quantitative and qualitative data analysis, our study provides insights into understanding the nuances in relation to underserved students' access to technology resources in online education, contributing to digital divide research.

The digital divide among underserved students is evolving and complex; addressing the issue needs to go beyond the generational status or socioeconomics background of students. Individual differences need to be accounted for. Digital divide research has shown that lower income and other socioeconomic factors (such as education and ethnicity) are correlated with a digital divide [27]. Our study extends the digital divide research by highlighting that the factors may differ, based on the population under study. For firstgeneration college students, our qualitative data analysis suggests that new factors such as employment status (i.e., full-time or part-time employment) and age are important in influencing the digital divide, if it persists. 
Practically, our findings highlight the importance of understanding individual differences in investing in technology resources for underserved students in higher education, echoing the call for more efforts to invest in the persistence and success of underserved college students [2]. When educational continuity was disrupted by the start of the COVID-19 pandemic in the spring of 2020, computer and Internet deficiencies emerged as two major barriers in the online education. To provide a remedy to overcome the digital barrier of students' lacking computer resources and suffering from slow or no Internet service, the study by Gan and Sun [3] in Spring 2020 recommended that higher education institutions consider implementing a tech loaner program that provides students, especially low-income, minority, and FGCS with free laptop computers and updated software sufficient for their online learning needs. Our study conducted one year later, in March 2021, did not find a significant gap between FGCS and CGCS in technology access at home. However, our study provided evidence to show a university's Technology Loaner program (supported by the federal CARES fund) was adopted by low-income underserved students significantly more than by their counterparts.

Our study also revealed FGCS obtained technology resources from other channels, including their twoincome families or employers. We performed Chisquare tests between FGCS and other demographic background variables (i.e., ethnic background and household income). The untabulated results of Chisquare tests showed that there was significant association between FGCS and ethnicity $(\mathrm{p}<0.05)$, and between FGCS and household income $(\mathrm{p}<0.05)$. These results further suggest dynamic and complex backgrounds of underserved students and the need to consider their unique backgrounds when designing programs to support underserved college students' experience and academic success.

\section{Concluding remarks}

The digital divide experienced by underserved students cannot be underestimated. However, the digital divide in online education was found between underserved students from low-income families (less than $\$ 40 \mathrm{k}$ ) and their counterparts. However, the digital divide was not demonstrated by the generational status or minority background of the underserved students in our study. The individual differences among the underserved students, such as their household income and employment status, need to be further examined and empirically tested by collecting a larger data sample.

We would like to acknowledge the limitations of this study: First, our samples of the CGCS (45 out of 258 ) and of the non-minority students (47 out of 258) are not large enough to make meaningful statistical comparisons. This limitation is partially addressed in our qualitative data analysis, which provides contextual information to explain students' experiences with digital barriers and their adoption of the Technology Loaner Program, but a future empirical study based on a larger survey would offer new insights. Second, the university in this study, as a minority-serving university, has a higher percentage of underserved students and firstgeneration college students than do private universities and most other public universities in the country. In universities where first-generation students are a minority, there may be more of a digital divide. Comparing the digital divide between FGCS and their peers in private universities or other public universities is likely to generate additional insights into closing digital resources gaps among college students.

Closing the gap in technology access and skills among underserved students and their counterparts is essential to achieving the underserved students' college persistence and success. As Van Dijk [34] posits, unequal distribution of resources leads to inequality in digital technological access, which in turn can lead to unequal participation in society that widens inequalities and the distribution of resources. Our study indicates that individual background should be considered in designing an educational policy to mitigate the digital divide. A policy based on assumptions regarding homogenous generational status or socioeconomic background may be ineffective, given the complex background of underserved students and the evolving nature of the digital divide in higher education.

\section{Acknowledgement}

This research was funded by the Office of the President at California State University Dominguez Hills for the awarded President's Challenge project entitled "Improving Diversity and Engagement for Equity and Inclusion."

\section{References}

[1] ACT Report, Understanding the underserved learners: The condition of STEM 2014, ACT Inc, 2014.

[2] M. A. Winkelmes, M. Bernacki, J. Butler, M. Zochowski, J. Golanics, and K. H. Weavil, "A teaching intervention that increases underserved college students' success", Peer Review, 2016, vol. 18, no. 1-2, pp. 31-36.

[3] I. Gan, and R. Sun, "Digital divide and digital barriers in distance education during COVID-19", Proceedings of the 54th Hawaii International Conference on Systems Science (HICSS -54), Hawaii, January 5-8, 2021, pp. 4838-4847. [4] S. S. Jaggars, B. A. Motz, M. D. Rivera, A. Heckler, J. D. Quick, E. A. Hance, and C. Karwischa. "The digital divide among college students: Lessons learned from the COVID- 
19 emergency transition", Midwestern Higher Education Compact, January 2021.

[5] D. Gunkel, "Second thoughts: toward a critique of the digital divide," New Media \& Society, 2003, vol. 5, no. 4, pp. 499-522.

[6] National Telecommunications and Information Administration (NTIA), "Falling through the net: defining the digital divide", NTIA, Washington, DC, 1999.

[7] RTI International, "First-generation college students: demographic characteristics and postsecondary enrollment", NASPA, Washington, DC, 2019.

[8] M. Azmitia, M. Syed, and K. Radmacher, "Finding your niche: Identity and emotional support in emerging adults' adjustment to the transition to college", Journal of Research on Adolescence, 2013, vol. 23, no. 4, pp. 744-761.

[9] J. Redford, and K. M. Hoyer, "First-generation and continuing-generation college students: a comparison of high school and postsecondary experiences (NCES 2018-009)", U.S. Department of Education, National Center for Education Statistics, Washington, DC, 2017.

[10] T. T. Ishitani, "Studying attrition and degree completion behavior among first-generation college students in the United States", The Journal of Higher Education, 2006, vol. 77, no. 5, pp. 861-885.

[11] K. C. Desouza, O. A. El Sawy, R. D. Galliers, C. Loebbecke, and R. T. Watson, "Beyond rigor and relevance towards responsibility and reverberation: Information systems research that really matters", Communications of the Association for Information Systems, 2006, vol. 17, no. 1, pp. 16.

[12] R. M. Davison, and N. Bjørn-Andersen, "Do we care about the societal impact of our research? The tyranny of the $\mathrm{H}$-index and new value-oriented research directions." Information Systems Journal, 2019, vol. 29, pp. 989-993. [13] L. Schudde, and J. Scott-Clayton, "Pell grants as performance-based scholarships? An examination of satisfactory academic progress requirements in the nation's largest need-based aid program", Research in Higher Education, 2016, vol. 57, no. 8, pp. 943-967.

[14] M. Cahalan, and L. Perna, "Indicators of Higher Education Equity in the United States: 45 Year Trend Report", Pell Institute for the Study of Opportunity in Higher Education, 2015.

[15] A. E. Stich, and T. D. Reeves, "Massive open online courses and underserved students in the United States", The Internet and Higher Education, 2017, vol. 32, pp. 58-71. [16] J. Engle, and V. Tinto, "Moving beyond access: College success for low-income, first-generation students", Pell Institute for the Study of Opportunity in Higher Education, 2008.

[17] G. M. Walton, and G. L. Cohen, "A brief socialbelonging intervention improves academic and health outcomes of minority students", Science, 2011, vol. 331, pp. 1447-1451.

[18] M. Azmitia, G. Sumabat-Estrada, Y. Cheong, and R. Covarrubias, “'Dropping out is not an option': How educationally resilient first-generation students see the future", New Directions for Child and Adolescent Development, 2018, vol. 160, pp. 89-100.

[19] S. E. Schwartz, S. S. Kanchewa, J. E. Rhodes, G. Gowdy, A. M. Stark, J. P. Horn, M. Parnes and R. Spencer,
'"I'm having a little struggle with this, can you help me out?': Examining impacts and processes of a social capital intervention for first-generation college students", American Journal of Community Psychology, 2018, vol. 61, no. 1-2, pp.166-178.

[20] K. G. Saw, O. Majid, N. Abdul Ghani, H. Atan, R. M. Idrus, Z. A. Rahman, and K. E. Tan, "The Videoconferencing learning environment: Technology, interaction and learning intersect", British Journal of Educational Technology, 2008, vol. 39, no. 3, pp. 475-485.

[21] P. Kirschner, J. Strijbos, K. Kreijns, and P. J. Beers, "Designing electronic collaborative learning environments", Educational Technology Research \& Development, 2004, vol. 52, no. 3, pp. 47-66.

[22] L. A. Jackson, K. S. Ervin, P. D. Gardner, and N. Schmitt, "The racial digital divide: motivational, affective, and cognitive correlates of internet use", Journal of applied social psychology, 2001, vol. 31, no. 10, pp. 2019-2046. [23] S. Jones, C. Johnson-Yale, S. Millermaier, and F. S. Pérez, "US college students' Internet use: Race, gender and digital divides", Journal of Computer-Mediated Communication, 2009, vol. 14, no. 2, pp. 244-264.

[24] A. J. A. M. Van Deursen, and J. A. G. M. Van Dijk, "Measuring digital skills", in Conference of the International Communication Association, May 2008.

[25] A. J. A. M. Van Deursen, and J. A. G. M. Van Dijk, "The first-level digital divide shifts from inequalities in physical access to inequalities in material access", New Media \& Society, 2019, vol. 21, no. 2, pp. 354-375.

[26] Van Dijk, J. A. G. M, The deepening Divide: Inequality in the Information Society, SAGE Publications, 2005.

[27] A. J. A. M. Van Deursen, and E. J. Helsper, "The thirdlevel digital divide: Who benefits most from being online?", Communication and Information Technologies Annual, Studies in Media and Communications, 2015, vol. 10, pp. 2952.

[28] T. Notley, "Young people, online networks, and social inclusion", Journal of Computer-Mediated Communication, 2009, vol. 14 no. 4, pp. 1208-1227.

[29] X. Deng and Z. Yang, "Digital Proficiency and Psychological Well-Being in Online Learning: Experiences of First-generation College Students and Their Peers", Social Sciences, 2021, vol. 10, no. 6, pp. 192.

[30] J. Mingers, "Combining is research methods: towards a pluralist methodology”, Information Systems Research, 2001, vol. 12 , pp. 240-259.

[31] U.S. Department of Education, List of postsecondary institutions enrolling populations with significant percentages of undergraduate minority students, 2021.

[32] X. Deng, and R. Sun, "Barriers to e-Learning during crisis: A capital theory perspective on academic adversity", Journal of Information Systems Education special issue on Equality, Diversity \& Education, 2021.

[33] Miles, M. B., and A.M. Huberman, Qualitative Data Analysis: An Expanded Sourcebook, Sage Publications: Thousand Oaks, 1994.

[34] J. A. G. M. Van Dijk, "Digital divide: Impact of access", The International Encyclopedia of Media Effects, 2017. 